\title{
Legitimation in Moroccan Policy Texts
}

\author{
Badia Elharraki \\ Faculty of Letters, Fez-Saiss \\ PO Box 59, Route Imouzzer, CP 3000, Fes, Maroc \\ Tel: 212-535-618-226. E-mail: badiamst@hotmail.fr
}

Received: April 29, 2019 Accepted: June 26, 2019 Published: July 1, 2019

doi:10.5296/elr.v5i2.14721 URL: https://doi.org/10.5296/elr.v5i2.14721

\begin{abstract}
This paper scrutinizes the key discourses present in the policy texts about women subject to violence in Morocco in order to examine the macrostructures that constitute the backbone of these documents. The overall objective is to see whether the discourse prevalent in the policy environment and articulated in a specific document named "Tamkine" opposes or agrees with the human rights discourse. It will be shown that the official government and the human rights one constitute two different poles in their approach to gender violence in Morocco.
\end{abstract}

Keywords: Violence against women, Discourse Analysis, Tamkine, Human rights

\section{Introduction}

A study of the key discourses that prevail in the policy texts about women subject to violence (WSV) in Morocco is meant to serve the purpose of figuring out the key macrostructures in the documents under study and to check whether the discourses that were established in the policy environment are consistent or opposing with human rights discourse. As a matter of fact, we have followed the same line of argumentation developed by van Dijk (2009), who starts Critical Discourse Analysis (CDA) with an analysis of the semantic macrostructures in a text to spot the global meanings and the dominant themes of interest to textual processing. We have chosen "Tamkine" (Ministry of Social Development, family and solidarity, 2008) as a representative document that reflects the official position of the state vis-à-vis the problem of violence against women as this multisector program has been advertised by the Moroccan government as an efficient strategy to eradicate the phenomenon of violence against women and strengthen the culture of human rights in Morocco. Tamkine program, which was launched in March 2008 and which integrates 13 sectors and $8 \mathrm{UN}$ agencies, aims, among other things, to strengthen Morocco's international commitment to the fight against violence, especially the one based on gender. 


\section{Macrothink}

\section{Some Key Issues in Discourse Analysis and Critical Discourse Analysis}

\subsection{Discourse Analysis}

The scope of Discourse Analysis (DA) encompasses knowledge about language beyond the word, the phrase, the clause, and the sentence to embrace patterns of language across texts, and the relationship between language and the social and cultural setting where it is implemented. It also covers the various ways in which language presents different views of the world and different conceptualizations. The use of language under the influence of relationships between participants, the effects the use of language has upon social identities and relations, in addition to how views of the world and identities are constructed through the use of discourse constitute its basic ingredients. All these elements are examined in both spoken and written texts (Paltridge, 2006, p. 2). In other words, DA, as a sub-field of linguistics, studies the ways sentences and utterances go together to make texts and interactions, and how those texts and interactions fit into our social world.

\subsubsection{Context and Discourse}

Context has been classified differently by different linguists. Lichao Song (2010), for example, identified context along the following lines:

\subsubsection{Linguistic Context}

At this level of discoursal context, the relationship between the words, phrases, sentences and even paragraphs is highlighted. This category of context can be approached from three points: deictic (like reference to time, place and person expressions), co-text (like reference to other previous texts), and collocation (syntagmatic relations) (Lichao Song, 2010, p. 876).

\section{1.1.2 Situational Context}

This type of context has to do with the environment (temporal and spacial) where any piece of discourse takes place, in addition to participants .For her, this variable is conventionally handled within register theory as propounded by Halliday, a theory that links language to context via three elements: the well-known field, tenor, and mode (Lichao Song, 2010, p. 877).

\section{1.1.3 Cultural Context}

Being a social product, language is necessarily linked with the social structure and value system of society, where the influence of factors like social role, social status, sex and age, etc... is important (Lichao Song, 2010, p. 877).

For Van Dijk (1988, p. 29), any DA should mix the text and the context of use; in other words, the use of a discourse in a social situation is at the same time a social act. This view dictates a thorough consideration of the relevance of the two key elements (society and context) in all analyses.

Harris (1952) was among the first linguists to scrutinize the relationship between linguistic and non-linguistic behavior to tackle the important issue of how people know from the 
situation they are in and how they interpret what someone says. This moves linguistic analysis to an interest in what happens when people use their linguistic knowledge to do things in the world (Johnstone, 2002, p. 3): it is thus the analysis of language in use. For Chimombo and Roseberry (1998), the objective of DA is to understand and appreciate texts, spoken or written, and to highlight how these texts become meaningful to their users.

A real grasp of the functions of language in context is of paramount importance to an understanding of the relationship between what is said and what is understood in discourse. The context of situation of what someone says is crucial to understanding and interpreting the meaning of what is said. In this respect, an array of basic concepts of "context" relevant to the production and interpretation of discourse have to be enumerated, namely the situational context in terms of what people know about what they can see around them, the background knowledge context in terms of what people know about each other and the world (it includes cultural knowledge and interpersonal knowledge), and contextual knowledge which also includes social, political, and cultural understandings that are relevant to the particular communication (Celce-Murcia \& Olshtain, 2000).

Closely related to the notion 'context' is intertexuality as texts are not to be interpreted in isolation; in other words, texts are naturally interpreted against the background of other texts as we naturally make sense of language against the background of other stretches of language of a similar kind (lemke, 1992, 1995). The bottom line is that all texts are in an intertextual relationship with other related texts.

\subsubsection{Ideology and Discourse}

A crucial question in DA concerns the definition of 'ideology'. "Ideologies are particular ways of representing and constructing society which reproduce unequal relations of power, relations of domination and exploitation" (Fairclough \& Wodak, 1997, p. 275). Similarly, Fairclough (1992, p. 67) defines it as "significations generated within power relations as a dimension of the exercise of power and struggle over power". In its relation with language, it was maintained that language is not powerful on its own - it gains power by the use powerful people make of it.

Hall (1997) (Cited in Morley \& Chen, 1996, p. 26) describes this process as having "especially to do with the concepts and the languages of practical thought which stabilize particular forms of power and domination", the purpose of which is to "reconcile and accommodate the masses of the people to their subordinate place in the social formation."

The values and ideologies which underlie texts tend to be hidden rather than overtly stated. As Threadgold (1989) observes, texts are never ideology-free or objective, nor can they be separated from the social realities and processes they contribute to maintaining. For this author, spoken and written genres are not just linguistic categories but "among the very processes by which dominant ideologies are reproduced, transmitted and potentially changed" (p. 17). In her view, a spoken or written genre is never just the reformulation of a linguistic model, but always the performance of a politically and historically significant process. 
To conclude this section about key issues in DA, we should make it clear that all the elements we have exposed so far provide an explanation to language variation, a sociolinguistic concept which refers to the fact that speakers often have a repertoire of social identities and discourse community memberships. People have a number of varieties they use to communicate in their particular communities. Generally, opting for a specific variety is governed not only by the domain the language it is used in, such as with family, among friends, in a mosque, etc...., but also by social factors such as addressees, the topic, function and goal of the interaction, social distance between speakers, the formality of the setting or type of the interaction and the status of each of the speakers (Holmes, 2001), in addition to ideological considerations.

\subsection{Critical Discourse Analysis}

Fairclough (1992, p. 72) perceives the framework of CDA as "an attempt to bring together three analytical traditions, each of which is indispensable for discourse analysis". We have textual and linguistic analysis within linguistics; macrosociological analysis of social practice in relation to social structures, and the interpretivist or microsociological approach to social practice as something which people actively produce and make sense of on the basis of shared commonsense procedures.

In the light of the above understanding of discourse, van Dijk (1998) defines CDA as a field that sets as an object the study and analysis of texts to disclose the sources of power, dominance, and inequality at the level of discourse. Specifically, it inspects the way these sources are managed to be kept unchanged and reproduced in their social, political and historical environments. Similarly, Fairclough (1993) defines CDA as DA which aims at discovering the relationships between discursive practices, events and texts and the larger social/cultural context to identify "ideologically shaped relations of power and struggles over power" (p. 135).

We can say that CDA aims at spotting the prominent textual features of a text to decode the ideologies implicit within the representations and grammatical structure of the discourse. It is multidisciplinary in that it seeks to unravel the nature of social power and dominance by making explicit the intricate relationships between text, talk, social cognition, power, society and culture (Van Dijk, 1995). Being a cross-discipline approach within applied Linguistics, and a relatively new branch of DA, it emanated from research within various disciplines in the 1960's and early 1970's ranging from linguistics, semiotics, to psychology, anthropology and sociology in addition to the social theories of Foucault, Bordieu, and Habermas as well as the linguistic theories of Halliday (Burns, 2001, p. 138; McCarthy, 2006, p. 5). The main difference between DA and CDA relates to the fact that the former studies relationships between language and its contexts of use whereas the latter tackles issues of language, power and ideology within the discourse of texts (Coffin, 2001, p. 99; McCarthy, 2006, p. 5). Fowler (1981, p. 25 cited in Jaworski and Coupland, 2006, p. 27) states that: "[To be critical within CDA means to produce] a careful analytic interrogation of the ideological categories, and the roles and institutions and so on, through which a society constitutes and maintains itself and the consciousness of its members...All knowledge, all objects, are constructs: criticism 
analyses the processes of construction and, acknowledges the artificial quality of the categories concerned, offers the possibility that we might profitably conceive the world in some alternative way."

CDA attempts to stress how language is used within texts to construct specific ideological positions that entail unequal relations of power; in this way, $\mathrm{CDA}$ focuses on the linguistic dimensions of language, and at the same time maintains a strong political agenda in reference to how the language is used (Coffin, 2001, p. 99).

In this critical approach, texts are not neutral and "all texts are critical sites for the negotiation of power and ideology" (Burns, 2001, p. 138). For Fairclough (1989), CDA is a really helpful tool for understanding the relationships within language because of its Hallyidayan view of language where language is inseparable from its socio-linguistic context, its mediation of ideology and its relation to power structures within society. A characterization of the linguistic mechanisms through which ideology is constructed gives CDA an invaluable resource to crystallize the hidden methodology an author adopts in discourse to enclose representations of the world, consciously or unconsciously.

\section{Tamkine as a Government Policy Text}

In Discourse and Social Change, Fairclough (1992) states that his objective is to analyze discourse as a political and ideological practice. He believes that there is a one-to-one relationship between ideology and discourse, which means there is a one-to-one relationship between politics and discourse. Van Dijk (1997) came up with few criteria to know whether we have a political discourse in hand. Applying some of these criteria to our document, we find the following:

1). In the document named Tamkine, politicians (decision makers) are the actors or authors (Van Dijk 1997, p. 13) of the political discourse. The discourse of the WSV, who are "participants in the political process", is excluded although they are considered the main recipients.

2). The context of the document is political as it is located in a communicative event consisting of devising a plan to solve a problem that has political causes and consequences.

3). The principal political process in Tamkine is integration through agendas and policies by politicians.

4). The purpose is to share the same political values (like equality among women and justice nationwide).

Ball posits that public policies are ways of "representing, accounting for and legitimating political decisions. Policies are articulated both to achieve material effects, and to manufacture support for those effects" (Ball, 1998, p. 124).

\section{Macrostructures in Tamkine}

In his analysis, Van Dijk (1988) accounts for structures at various levels of description that includes levels from two different scopes. The first scope (the microstructural level) includes 
grammatical, phonological, morphological and semantic components whereas the second scope (the macrostructural level) includes higher level features like coherence, overall themes and topics, etc... The analysis of macrostructure has a special status in Van Dijk's analysis as it belongs to the thematic/topic structure of the texts and their general scheme. This level contains notions such as 'topic', 'theme' or 'gist' of a text that extend beyond microstructural elements to embrace the global scope of the text (Van Dijk, 1985, pp. 74-75).

Generally, macrostructures are structures that organize texts globally whereas microstructures organize them locally. Since texts are not merely agglutinations of sentences, they need to be organized at the local level (clauses and sentences should be linked together) and also at the global level e.g. at the level of paragraphs and higher units of organization. Whereas syntactic rules, together with semantic ones and general heuristics of discourse form the microstructure of a text, macrorules transform these sequences of propositions into a smaller set of more general propositions by the deletion of less important propositions for the general meaning of the text, by the generalization of propositions into supersets and by the construction of new text units that replace the meaning of the old set. Macrostructures are therefore abstract semantic descriptions of the semantic content of the text, similar to the text's global meaning. (Louwerse \& Graesser, in press, p. 4).

Although we perceive the document Tamkine as a political discourse, we will treat it like any ordinary discourse. Specifically, we will handle it from a discursive and social practice angle. To accomplish this, we will first break down the document into its major semantic macrostructures in order to see the type of legitimation politicians seek to achieve. The main semantic propositions that are threaded in the document named Tamkine and which we have extracted from an undated report by Saida Drissi Amrani (Head of Division, Women's Affairs at the Ministry for social development, family and solidarity, Morocco) named "Tamkine Program: Combatting violence against women in Morocco" are the following:

Morocco is determined to establish basic human rights. The legal and political reforms reflect this and reflect Moroccan commitment internationally to fight violence in general and gender-based violence specifically.

TAMKINE aims at achieving progress in gender equality, the protection of the rights of women and girls and their participation in political, economic, social and cultural life.

This involves 13 ministerial departments in Morocco, 8 United Nations agencies (UNIFEM, UNFPA, UNICEF, UNESCO, FAO, UNAIDS, UNHCR and ILO) and a large number of NGOs.

TAMKINE attempts to protect women and girls against all forms of violence: physical, verbal, psychological, sexual and economic.

This is done through finding a cure to their condition of poverty and vulnerability, and but above all, and through stressing the medium of the combat: the empowerment of women and girls.

TAMKINE is also intended to benefit migrant or refugee women and girls. The actions 
include, among other things, better access for women, including migrants and/or refugees, to quality services like support in addition to economic, social and political empowerment. The institutionalization of these individual and family (micro level) changes and their dissemination at social level are also central to the TAMKINE Programme.

The strategies used are: the advocacy actions of civil society, the capacity building of the institutional stakeholders in the area of gender-based violence, the development of data on this violence and finally the institutionalisation of territorial coordination mechanisms between stakeholders involved in protecting female victims of violence and their empowerment.

The program is being implemented in 6 of the Kingdom's 16 regions, identified on the basis of criteria combining poverty and gender disparity rates (illiteracy/early school leaving/unemployment).

\section{Legitimation in Tamkine}

The theory of legitimation explains how social order is established. Van Leeuwen (2007, p. 92) provides four categories of legitimation:

-Authorization i.e., legitimation by reference to the authority of tradition, custom and law, and of persons in whom institutional authority of some kind is vested.

- Moral evaluation i.e., legitimation by (often very oblique) reference to value systems.

- Rationalization i.e., legitimation by reference to the goals and uses of institutionalized social action and to the knowledge society has constructed to endow them with cognitive validity.

- Mythopoesis i.e., legitimation conveyed through narratives whose outcomes reward legitimate actions and punish non-legitimate actions.

Many studies have already exploited these categories (cf. Morgan, n. d.; Mullins, 2012), The four legitimation categories that have been posited by Van Leeuwen (2007): authorization, moral evaluation, rationalization and mythopoesis are used by the speaker separately or in combination to legitimize the speaker's position and delegitimize his opponents'. For space considerations, we will exemplify each category with just one macrostructure.

\subsection{Moral Legitimation}

Moral evaluation is used to legitimate actions based on moral values, rather than to impose actions. Tamkine uses a range of discursive strategies to invoke moral evaluations.

"The fight against violence against women and girls and the empowerment of women are a major concern in Morocco" (Drissi Amrani, n. d., para. 2) points towards the gravity of the issue of violence against Moroccan women and girls so much so that it is qualified as a major issue, a thing that constitutes a moral and ethical reason to take direct action to combat it.

\subsection{Authorization}




\section{I Macrothink}

“The legal and political reforms implemented in Morocco in recent years reflect the country's determination to establish fundamental human rights and reinforce its international commitment to combating violence, in particular gender-based violence" (Idrissi Amrani, n.d., para.1).

"In this context, the TAMKINE ("empowerment" in Arabic) Programme, launched in Marrakech on 30 May 2008, is part of the policy of eliminating violence against women through the attainment, according to one of the results of the United Nations Development Assistance Framework for Morocco (UNDAF), of "significant progress as regards gender equality, the protection of the rights of women and girls and their participation in political, economic, social and cultural life."'(Idrissi Amrani, n.d., para. 3).

These two statements highlight clearly this authoritative aspect of the government movement to combat violence through a deliberate reference to institutional power that grants it the capability to "establish" and "to reinforce". The reference to the international community implies that people grant this power to be represented at the international level through its different instances.

\subsection{Rationalization}

"the aim of TAMKINE is above all to prevent and protect women and girls against all forms of violence (physical, verbal, psychological, sexual and economic) by establishing the direct link between their condition of poverty and vulnerability, but above all, and this is one of the fundamental characteristics of the Programme, by emphasising the means by which the combat must be carried out moving forward, namely the empowerment of women and girls" (Idrissi Amrani, n.d., para. 5).

This a rationalized statement in the sense that it associates the problem with a sound solution and hence this problem-solution structure is empirically verifiable as everybody would agree that the ideal solution for the eradication of violence is empowerement, which is in itself a form of theoretical legitimation based on how things should be carried out.

\subsection{Mythopoesis}

"Financed by the Spanish Cooperation in the framework of the Fund for the Attainment of the Millennium Development Goals (MDGs), the aim of TAMKINE is above all to prevent and protect women and girls against all forms of violence (physical, verbal, psychological, sexual and economic)"(Idrissi Amrani, n. d. para. 5).

It is clear that this key proposition sends a message that sets the general goal of the programme as one that tries to solve a problem by surely helping women, but at the same time by implicitely punishing and delegitimizing the other category of people who may be perceived as the perpetuators of women's sufferings.

\section{Human Rights Discourse}

All the recommendations mentioned above are not sufficient for human rights organizations which assert that Morocco has a long way to run before it becomes a state that respects 
human rights in general and women's right specifically. A brief look at the 2013 Amnesty International report reveals an opposing discourse that counters the claims propagated by the government. The following representative blocks taken from the report give a hint about the opposition inherent in their semantic macrostructures:

Legislative reforms to bring Moroccan law in line with international human rights law and standards are crucial for women (p. 7).

The law and ingrained societal attitudes lead to discrimination against women, as has been the case in the application of Article 475 (p. 7).

Amnesty International urges the Moroccan authorities to comply with their obligations under Article 5 of the UN Convention on the Elimination of all forms of Discrimination Against Women (CEDAW) (p. 8).

This elimination should be accomplished through measures to change conduct of men and women to achieving the elimination of all practices which are based on the idea of the inferiority or the superiority of either of the sexes or on stereotyped roles for men and women" (p. 8).

These measures should include training of police and the judiciary on how to deal sensitively with complaints of violence against women and girls, and protect victims themselves, not their so-called "honour" or "morals" (p. 8).

Article 19 of the new Constitution adopted in July 2011 guarantees equality between men and women. However, equality is guaranteed "within the provisions of the Constitution and of Moroccan law", provisions of which are discriminatory against women, such as in matters of inheritance (p. 8).

The lifting of its reservations to Articles 9 and 16 of the CEDAW in April 2011, and the fact that in November 2012 the government began the process to enable Morocco to become party to the Optional Protocol to CEDAW are welcome steps. However, as long as Morocco continues to qualify its obligation to eliminate discrimination against women and to maintain discriminatory legislation, women will be treated unequally not only in practice but also in law (p. 8).

Amina Filali was failed by the law and the Moroccan authorities. They must urgently overhaul the Penal Code to ensure that no discriminatory provision is maintained and that the victims of gender-based violence in Morocco know that the law is there to protect them rather further victimize them (p. 8).

In her article, Szczepanik (n. d.) tried to analyze human rights discourse from a CDA perspective in order to scrutinize the bond between human rights, power and language. She found that "it serves as a tool to trace underlying asymmetrical relations between the actors of international politics entangled in the powerful discourse of human rights that conceals actual political interests. As such, it becomes prone to discretionary interpretations and manipulation, so that it can correspond to hidden agendas of political actors". She adds that there are "concerns of postcolonial societies about Western power being exercised under the disguise 
of "human rights protection"” (p. 21). She finishes by concluding that CDA shows that the term human rights is ambiguious and that the notion of universalism is false.

As far as we are concerned, we think that while the discourse of human rights may have hidden agendas, it remains that this discourse counterbalances the one propounded by the state and fathoms its weaknesses, a thing that may serve the official instances to devise redressive measures to cater for the potential needs of WSV. The annual reports of human rights organizations put a constant pressure on the state to ameliorate the situation of women and this is a positive asset no matter how critical we can be of these organizations and agendas. It is only natural to have two differently polarized forms of discourse: a positive and promising one characterizing the official one, embedded in an ideological system that tries to create social peace and stability, and a negative and critical one characteristic of human rights institutions that does not overlook any detail related to the grim situation of women in the third world and in Morocco.

\section{Conclusion}

From our experience with analyzing WSV discourse that we could not include in this paper due to time and space constraints, we notice its strong concordance with human rights one, and its disagreement with the official discourse. We can understand that whereas the official government discourse is implementational as while the political actors "talk", they also have the burden of concretizing the talk on the ground, human rights activists "talk and wait" for results. These two approaches to the phenomenon are surely two different constitutive discourse components and this also shows that a "comparative critical discourse analysis" may be a viable option in future research to problematize and debate the notion of ideology and power in discourse.

\section{References}

Amnesty International. (2013). Morocco/Western Sahara: Comprehensive reforms to end violence against women long overdue. Amnesty International Publications. Retrieved from https://www.amnesty.org/download/Documents/16000/mde290012013en.pdf

Amrani, S. D. (n. d.). Tamkine programme: Combatting violence against women in Morocco.

Ball, S. (1998). Big policies/Small world: An introduction to international perspectives in education policy. Comparative Education, 34(2), 119-130. https://doi.org/10.1080/03050 069828225

Burns, A. (2001). Analysing spoken discourse: Implications for TESOL. In A. Burns, \& C. Coffin (Eds.), Analysing English in a global context: A reader (pp. 123-148). Oxon: Routledge.

Celce-Murcia, M., \& Olshtain, E. (2000). Discourse and context in language teaching. Cambridge: Cambridge University Press.

Chimombo, M., \& Roseberry, R. (1998). The power of discourse: An introduction to Discourse Analysis. New Jersey: Lawrence Erlbaum Associates. 


\section{Macrothink}

Education and Linguistics Research

ISSN 2377-1356 2019, Vol. 5, No. 2

Coffin, C. (2001). Theoretical approaches to writing language-A TESOL perspective. In A. Burns, \& C. Coffin (Eds.), Analysing English in a global context (pp. 93-122). London: Routledge.

Fairclough, N. (1989). Language and power (2nd ed.). New York: Longman.

Fairclough, N. (1992). Discourse and social change. Cambridge: Polity Press.

Fairclough, N. (1993). Critical Discourse Analysis and the Marketisation of Public Discourse: The Universities. Discourse \& Society, 4(2), 133-168.

Fairclough, N., \& Wodak, R. (1997). Critical Discourse Analysis. In T. A. Van Dijk (Ed.), Discourse studies. A multidisciplinary introduction, Vol. 2. Discourse as social interaction (pp. 258-84). London: Sage.

Harris, Z. (1952). Discourse Analysis. Language, 28, 1-30.

Holmes, J. (2001). An introduction to sociolinguistics. London: Longman.

Jaworski, A., \& Coupland, N. (Eds.). (2006). The Discourse reader. London and New York: Routledge.

Johnstone, B. (2002). Discourse Analysis. Oxford: Blackwell.

Lemke, J. L. (1992). Intertextuality and educational research. Linguistics and Education, 4(3-4), 257-268. https://doi.org/10.1016/0898-5898(92)90003-F

Lemke, J. L. (1995). Textual politics: Discourse and social dynamics. London: Taylor \& Francis.

Lichao, S. (2010). The role of context in discourse analysis. Journal of Language Teaching and Research, 1(6), 876-879.

Louwerse, M. M., \& Graesser, A. C. (in press). Macrostructures. In E. K. Brown (Ed.), The encyclopedia of language and linguistics. Amsterdam: Elsevier.

McCarthy, M. (2006). Discourse Analysis for language teachers. Cambridge: Cambridge University Press.

Ministry of Social Development, family and solidarity. (2008). Tamkine. Marrakech: MDG

Achievement Fund.

Morley, D., \& Chen, K. H. (1996). Stuart Hall: Critical dialogues In cultural studies. London: Routledge.

Mullins, S. L. (2012). Narrative, education policy and the newsprint media: A critical discourse analysis of the construction of young people's participation in education or employment (Unpublished Ph.D thesis). Queensland University of Technology.

Paltridge, B. (2006). Discourse Analysis: An introduction. London: Continuum.

Szczepanik, M. (n. d.). The human rights discourse and the question of power: Application of 


\section{Macrothink}

Education and Linguistics Research

ISSN 2377-1356 2019, Vol. 5, No. 2

Critical Discourse Analysis to the study of the human rights language. International Journal of Rule of Law, Transitional Justice and Human Rights, 13-23.

Threadgold, T. (1989). Talking about genre: Ideologies and incompatible discourses. Cultural Studies, 3, 101-107. https://doi.org/10.1080/09502388900490071

Van Dijk, T. (1985). Introduction: DA as a new cross-discipline. In T. A. van Dijk (Ed.), Handbook of Discourse Analysis (pp. 1-10).

Van Dijk, T. (1988). News as discourse. New Jersey: Erlbaum Associates.

Van Dijk, T. (1995). Discourse, semantics and ideology. Discourse and Society, 6(2), 243-289. https://doi.org/10.1177/0957926595006002006

Van Dijk, T.(1997).What is political discourse analysis. In J. Blommaert, \& C. Bulcaen (Eds.), Political linguistics (pp. 11-52). Amsterdam: Benjamins.

Van Dijk, T. (1998). Ideology: A multidisciplinary approach. London, England UK: Sage Publications.

Van Dijk, T. (2009). Critical discourse studies: A sociocognitive approach. In R. Wodak, \& M. Meyer (Eds.), Methods of critical Discourse Analysis (pp. 62-86). London: Sage.

Van Leeuwen, T. (2007). Legitimation in discourse and communication. Discourse and Communication, 1(1), 91-112. https://doi.org/10.1177/1750481307071986

\section{Copyright Disclaimer}

Copyright reserved by the author(s).

This article is an open-access article distributed under the terms and conditions of the Creative Commons Attribution license (http://creativecommons.org/licenses/by/3.0/). 